\title{
QUEM DISSE QUE AS QUESTÕES RACIAIS NÃO AFETAM OS BEBÊS?
}

Circe Mara Marques ${ }^{1}$

Leni Vieira Dornelles ${ }^{2}$

\section{INTRODUÇÃO}

Novos paradigmas para as relações humanas se apresentam à sociedade do século XXI, exigindo não somente políticas econômicas como também políticas educacionais e culturais de combate a todo tipo de desigualdades.

Ao longo da história brasileira, produziram-se discursos monoculturais e eurocêntricos, os quais ainda hoje são disseminados nas ruas, nas igrejas, nos clubes, nas mídias e, também, em alguns currículos escolares e materiais didáticos, conforme mostram estudos de Cavaleiro (2000), Romão (2000; 2005), Oliva (2003; 2012), entre outros. Hoje coexistem situações concretas, naturalizadas e recorrentes de racismo, e uma legislação, a começar pela Constituição Federal de 1988, que criminaliza qualquer tipo de discriminação.

Mais de cinquenta por cento da população brasileira ${ }^{3}(54 \%)$ está constituída por pessoas que se declaram como negras e pardas, de modo que a escola não pode restringir-se a ensinar conteúdos desvinculados dessa realidade social e cultural (IBGE, 2010). Considera-se que

\footnotetext{
Mesmo tendo sido superado o olhar de superioridade com viés biológico, os resquícios sociais da hierarquização cultural continuam habitando os imaginários e moldando os olhares dos sujeitos, trazendo prejuízos gravíssimos à construção de uma sociedade plural e que respeita a diversidade que a compõe. (FLORIANÓPOLIS, 2016, p. 17).
}

\footnotetext{
${ }^{1}$ Doutora em Educação (UFRGS); Pós-doutora em Educação (UFRGS); Pós-doutoranda em educação pela UMINHOPT. Professora no curso de Mestrado Acadêmico Interdisciplinar em Desenvolvimento e Sociedade e no curso de Mestrado Profissional em Educação Básica na Universidad Alto Vale do Rio do Peixe circemaramarques@gmail.com

${ }^{2}$ Doutora em Educação (UFRGS); Pós-doutora em Educação pela UMINHO-PT. Professsora na UFRGS. lvdornelle@gmail.com

3 Ainda pode-se considerar a possibilidade de esse número ser ainda maior, pois muitas pessoas, por sentirem-se pejoritariamente marcadas, optam por omitir ou negar seus traços identitários.
} 
Não se trata de deslocar o foco do currículo escolar de matriz eurocêntrica para uma raiz africana, mas de abrir esse currículo para outras matrizes culturais, como está previsto nas Diretrizes Curriculares para a Educação das Relações Étnico-raciais (BRASIL, 2009).

As questões raciais devem fazer parte da formação humana (GOMES, 2005) e é tarefa dos professores, em parceria com as famílias, criem condições de possibilidade para que outros modos de se relacionar com as diferenças sejam vividos por jovens e crianças na escola.

A Constituição Federal do Brasil (1988), a Lei No 8.069/1990, a Lei № 9394/96 (LDBEN), a Lei $N^{\circ} 10.639 / 03$ são marcos legais para práticas de igualdade racial na sociedade. Esse conjunto de documentos destaca as contribuições das diferentes culturas e etnias para a formação do povo brasileiro, asseguram a igualdade de direitos e de condições para a permanência de todas as crianças na escola, bem como tornam obrigatório o ensino de História e Cultura Afro-brasileira e Africana nos estabelecimentos de ensino fundamental e médio das escolas brasileiras, públicas e particulares.

Contudo, uma legislação justa é importante, mas não basta para promover igualdade racial (DIAS, 2012). A lei somente será eficaz se produzir mudança na realidade e resultar em ações concretas em diferentes instâncias da sociedade, entre elas, a escola. Também não basta refletir sobre a realidade, criticar as injustiças, prometer mudanças. É preciso inventar outras práticas pedagógicas. Então cabe indagar em que medida a escola, através de seus professores e gestores, tem trabalhado no sentido de problematizar as relações de poder e inventar estratégias para romper os discursos que se fundam na suposta superioridade das pessoas de pele branca em relação às de pele negra?

Em se tratando do contexto da Educação Infantil, cabe destacar que a Resolução no 5 , de 17 de dezembro de 2009, que fixa as Diretrizes Curriculares Nacionais para a Educação Infantil (DCNEI), especifica que as diferentes culturas devem ser observadas na organização de propostas pedagógicas nessa etapa da educação básica. No Artigo $7^{\circ}$, inciso $\mathrm{V}$, desse documento, fica assegurado o compromisso com o rompimento das relações de dominação diversas, inclusive, étnico-raciais, na elaboração das propostas pedagógicas para crianças de 0-5 anos. Na sequência, Art. $8^{\circ}$, incisos VIII e IX determinam que seja garantida às crianças a apropriação das contribuições histórico-culturais dos diferentes povos que constituem a nação brasileira, bem como o combate ao racismo e à discriminação.

O objetivo dessa investigação-ação foi discutir acerca do trabalho pedagógico relacionado às culturas afro-brasileiras que está sendo realizado para implementar as Diretrizes Curriculares 
Nacionais para a Educação Infantil (DCNEI/2009) e romper com a invisibilidade do tema desde o berçário.

Nesse sentido, consideramos que "A invisibilidade não é uma ação inofensiva, inconsciente ou ingênua. Quando gerida pelas instituições, a invisibilidade pode ser considerada um mecanismo do racismo institucional". (FLORIANÓPOLIS, 2016, p. 17).

As especificidades da ação pedagógica com bebês são um desafio para a implementação das DCNEI nas escolas brasileiras (BRASIL, 2010, p. 31). Durante muito tempo a criança pequena foi descrita por suas fragilidades, suas incapacidades e sua imaturidade. Estudos como os de Richter e Barbosa (2010) nos mostram que o bebê "É muito ágil e inventivo; é poderoso em sua capacidade básica de se auto-organizar, autogerir, autoadministrar, escolher e tomar decisões para empreender ações e alcançar êxito nos resultados” (p. 87). Também as pesquisas de Guimarães (2008), Gobatto (2011), Correa (2013), Vargas (2014), Mallmann (2015), entre outros, vêm dando visibilidade à potência dos bebês e desafiando a pensar um currículo 'outro' para crianças de 0-3 anos. Currículo esse que "não deve propor que as crianças abandonem a sensibilidade para construir a razão, mas justamente deve instigá-las a conviver e potencializar sua imaginação, sensibilidades, sensorialidades, percepções, ações em pensamentos, lógicas experiências cada vez mais complexas (RICHTER e BARBOSA, 2009, p.30).

Através das interações e brincadeiras vividas com o seu corpo, com os seus pares e com os adultos é que as crianças pequenas constituirão significados relacionados ao patrimônio cultural, dentre esses, seu modo de agir em relação às pessoas diferentes de si. Uma educação antirracista na infância, então, deve passar pela ludicidade e pela qualidade da intervenção do professor quando organiza tempos, espaços e materiais. Em pesquisa desenvolvida com crianças de cinco anos que frequentam uma escola de educação infantil de Porto Alegre, Dornelles e Kaercher (2012) observaram que as crianças davam preferência às bonecas brancas, contudo algumas delas se contentavam com as bonecas negras quando não conseguiam as brancas para brincar.

Ainda os estudos produzidos, a partir de brincadeiras com bonecas de diferentes tipos de corpos na educação infantil, nos mostram que as crianças de 0-5 anos estão acostumadas com o corpo branco, limpo, magro e completo das bonecas, sendo que aquelas que se afastavam desse padrão causavam certo estranhamento (MARQUES, 2013; DORNELLES e MARQUES, 2015). Tais crianças, durante as brincadeiras, expressavam sentimentos condolentes em relação às bonecas com deficiências físicas ou sensoriais, sendo que organizavam brincadeiras de médico ou de hospital para medicalizar e curar o corpo dos brinquedos. As bonecas negras, contudo, provocavam 
sentimentos de repulsa e, em dados momentos, chegavam a ser rechaçadas. Nesse sentido, não cabe ao professor dar "lição de moral" ou repreender as crianças, mas, garantir desde muito cedo, experiências lúdicas que abracem as diferenças. Assim, seu papel "efetiva-se na construção de um espaço educacional que favoreça, através da interlocução com as crianças e as famílias, experiências nas diferentes linguagens e nas práticas sociais e culturais de cada comunidade" (RICHTER e BARBOSA, 2010, p. 85).

Destacamos a necessidade de problematizar o modo como questões étnico-raciais vêm sendo apresentadas à infância e a importância de que essa temática seja trabalhada na formação de professores, abarcando não só “a dimensão investigativa (pesquisa), mas também interventiva, no sentido de transformação da realidade étnico-racial conflitiva na qual as crianças, negras ou não, vêm sendo educadas" (DORNELLES e KAERCHER, 2012, p. 9).

\section{CAMINHOS DA PESQUISA}

A pesquisa foi feita em onze escolas de Educação Infantil, três públicas e oito privadas, localizadas na região metropolitana de Porto Alegre, durante o primeiro semestre de 2015. Realizou a coleta de dados um grupo de quinze estudantes do curso de Pedagogia, matriculadas na disciplina de Educação Infantil em uma instituição privada de ensino superior, localizada na mesma região. Inicialmente as pesquisadoras orientaram leituras e promoveram discussões com o grupo de estudantes. Foram selecionados para leitura os seguintes materiais disponibilizados no site do Ministério da Educação:

\section{LEITURAS OBRIGATÓRIAS PROPOSTAS ÀS ESTUDANTES DE PEDAGOGIA}

Lei 10.639/2003. Altera a Lei no 9.394, de 20 de dezembro de 1996, que estabelece as diretrizes e bases da educação nacional, para incluir no currículo oficial da Rede de Ensino a obrigatoriedade da temática "História e Cultura Afro-Brasileira", e dá outras providências. Poder Legislativo, DOU n8/02, seção I, p. I, Brasília, 2003.

BRASIL. Ministério da Educação. Secretaria de Educação Básica. Diretrizes

Curriculares Nacionais para a Educação Infantil. Secretaria de Educação Básica. Brasília: MEC, SEB, 2010.

BRASIL. Educação infantil e práticas promotoras de igualdade racial / [coordenação geral Hédio Silva Jr., Maria Aparecida Silva Bento, Silvia Pereira de Carvalho]. - São Paulo: Centro de Estudos das Relações de Trabalho e Desigualdades - CEERT :Instituto Avisa lá - Formação Continuada de Educadores, 2012.

BARBOSA, Maria Carmen S. As especificidades da ação pedagógica com os bebês. Brasília, MEC/Secretaria de Educação Básica, 2010. Disponível em: file:///C:/Users/user/Downloads/asespecificidadesdaacaopedagogica\%20(3).pdf Acesso em 16 de fevereiro de 2015. 
Foram realizados quatro encontros presenciais para discutir o material com as estudantes. A partir dessas leituras e discussões, o grupo foi instigado a construir questões semiestruturadas para compor o instrumento de pesquisa a ser aplicado nas escolas durante as entrevistas com gestores e professores. As questões buscaram investigar a presença dessa temática no Projeto Pedagógico da escola, o conhecimento de gestores e professores sobre o conteúdo da Lei e das DCNEI, a presença de referenciais afro-brasileiros nos espaços da escola e a existência de materiais pedagógicos nas salas, bem como os modos como a cultura Afro-brasileira é trabalhada com as turmas de 0-3 anos.

Feita a coleta de dados nas diferentes escolas pelas estudantes, as informações foram compartilhadas em um seminário. Consideradas as especificidades de cada contexto, com orientação das pesquisadoras, as estudantes planejaram as atividades e organizaram materiais didáticos na perspectiva de se desenvolverem práticas promotoras de igualdade racial com bebês e crianças pequenas. Então, retornaram às escolas com os materiais, desenvolveram as práticas nos berçários e documentaram essas experiências.

As práticas realizadas pelas alunas da Pedagogia estiveram documentadas, analisadas e apresentadas em um segundo seminário para o qual foram também convidados gestores e professores das onze escolas pesquisadas.

\section{O MITO DA EDUCAÇÃO INFANTIL COMO LUGAR ISENTO DE PRECONCEITO RACIAL}

No primeiro momento dessa pesquisa, buscamos produzir um levantamento acerca do modo como as culturas afro-brasileiras são apresentadas aos bebês e às crianças pequenas nas escolas pesquisadas. Os dados mostram um cenário inquietante, uma vez que além de prevalecer, entre as professoras e gestoras, o mito de que a educação infantil é um lugar isento de preconceito, observamos que essa temática quase não está contemplada, tanto nos Projetos Pedagógicos das escolas, como nos planejamentos das professoras. Nesse sentido é importante considerar que "Superamos a invisibilidade quando trazemos o tema e o sujeito do tema para o projeto político pedagógico". (FLORIANÓPOLIS, 2016, p. 18).

Essa situação é ainda mais grave quando nos atermos ao que é proposto às crianças de 0-3 anos, pois, segundo os discursos das gestoras e professoras, elas são muito pequenas e "incapazes de perceber as diferenças raciais". Outra justificativa apresentada pelas profissionais entrevistadas se refere ao fato de não haver nenhum bebê negro na turma. Esse discurso evidencia uma concepção 
a ser superada quando os estudos contemporâneos apontam para a potência dos bebês e crianças pequenas em suas relações com o mundo que os cerca.

Com relação aos recursos disponíveis na escola para trabalhar as questões raciais, vimos que a maioria das escolas possui acervo bastante limitado, ou seja, algumas bonecas negras e o livro de literatura infantil A Menina Bonita do Laço de Fita, da Ana Maria Machado. Esses poucos materiais ficam "guardados" em armários para serem mostrados às crianças em momentos pontuais do calendário nacional, como o do Dia da Abolição da Escravatura no Brasil e/ou Dia da Consciência Negra. Nesse sentido, entendemos que as crianças estão sendo privadas de brincarem e interagirem em seu cotidiano com referenciais da cultura africana e afro-brasileira.

Com relação às observações nos espaços das escolas pesquisadas, constatamos que há uma predominância de imagens de pessoas brancas, sendo que a única visualidade que remete ao negro foi a de um Saci Pererê ${ }^{4}$.

Por fim, nesse primeiro momento da pesquisa constatamos a necessidade de dar maior visibilidade ao que é possível realizar 'com' os bebês, inclusive quando se trata de diferença racial.

\section{ALGUNS MODOS DE BUSCAR UMA EDUCAÇÃO ANTIRRACISTA NOS BERÇÁRIOS}

A partir do que tratamos em aula e nos seminários, nos lançamos a organizar ações e planejamentos, produzir materiais didáticos para inventar modos de tratar sobre as culturas africanas e afro-brasileiras com as crianças.

As alunas confeccionaram materiais como bonecas, fantoches, dedoches, quebra-cabeças, tapetes, móbiles, cortinas, etc. Também utilizaram outros materiais não estruturados, como panos e lenços, para junto às crianças confeccionarem as roupas de princesas africanas criando penteados afros, tranças e dreadloks enfeitados com laços, turbantes coloridos, tic-tacs, piranhas e flores.

Construíram tendas e cortinas de fitas para delimitarem espaços de contação de histórias e brincadeiras com os bebês; utilizaram materiais que convidassem a espiar, cheirar, escutar, tocar,

\footnotetext{
${ }^{4}$ O Saci-Pererê é um dos personagens mais conhecidos do folclore brasileiro. Possui até um dia em sua homenagem: 31 de outubro. Provavelmente, surgiu entre povos indígenas da região Sul do Brasil, ainda durante o período colonial (possivelmente no final do século XVIII). Nessa época, era representado por um menino indígena de cor morena e com um rabo, que vivia aprontando travessuras na floresta. Porém, ao migrar para o norte do país, o mito e o personagem sofreram modificações ao receberem influências da cultura africana. O Saci transformou-se num jovem negro com apenas uma perna, pois, de acordo com o mito, havia perdido a outra numa luta de capoeira. Passou a ser representado usando um gorro vermelho e um cachimbo, típico da cultura africana. Até os dias atuais ele é representado desta forma. Disponível em: http://www.suapesquisa.com/musicacultura/saci-perere.htm Acesso em 30/05/2016.
} 
mover-se, etc. Confeccionaram tapetes e almofadas de chitão, de patchworks, de fuxicos coloridos, de modo que os bebês pudessem deslocar-se sobre estes espiando/passando através da cortina.

Uma das ações realizadas com uma turma de 3 anos, ocorreu sobre um tapete de chitão quando uma das professoras apresentou para o grupo a boneca Lelê, feita de pano e inspirada no livro de literatura infantil $O$ Cabelo de Lelê, de Valéria Belém. Com seus dreadlok a boneca apresentada fez com que os bebês ficassem muito atentos e quisessem pegá-la para tocar em seu cabelo. Após, contou a história mostrando as figuras do livro, sendo que as cores vibrantes das ilustrações despertaram ainda mais a atenção de todos. A professora conversava com as crianças sobre como é o cabelo de Lelê; quem tem os cabelos como o dela; quem se parece com a Lelê. Então, uma menina falou: -"Meu cabelo é igual da Lelê. A mãe bota piranha no meu cabelo pra ficar linda!".

Inspirada no livro, a professora sugeriu que as crianças brincassem com seus cabelos, criando penteados uns nos outros. Oportunizou diferentes tipos de materiais, tais como: piranhas pequenas, tiaras, lenços, flores, tic-tac, etc. A sala de aula virou um salão de beleza. Embora houvesse vários materiais, todos queriam as piranhas grandes e coloridas como a da colega negra que já havia vindo de casa com os cabelos enfeitados pela mãe. Toda a turma brincou com seus próprios cabelos e com os cabelos dos colegas, fossem eles lisos, crespos, loiros, escuros, carapinha, curtos, longos. Até a boneca Lelê foi penteada pelas crianças. Esse brinquedo passou a acompanhar as crianças nos momentos da roda, de lanche, de alimentação e nas brincadeiras do pátio. Também, visitou a casa de cada uma das crianças, sendo levada a cada dia por uma delas.

A visita da boneca, em um primeiro momento, causou estranheza para algumas famílias que diziam: "Meu filho nunca teve uma boneca assim, preta!", "Eu nunca comprei um boneca negra para minha filha!” e "Levar essa boneca pra casa, humm quero ver no que vai dar?!”.

As crianças, desde muito pequenas, aprendem na relação com os pares, com os adultos, com suas famílias, com os materiais/brinquedos, sendo que os professores podem assumir o desafio de, a cada dia, surpreendê-las nos espaços da sala, principalmente no que se refere a este tema.

Aprendemos com esses projetos que nos mobilizaram e nos mobilizam a tratar das questões raciais, desde os berçários, que o modo de organização dos espaços e os materiais ali disponibilizados precisam instigar a curiosidade, a brincadeira, a necessidade de viver a experiência de olhar, escutar, mexer, tocar e viver com aquele que é diferente de si. Descobrimos também que tratar deste tema com as crianças bem pequenas possibilita que professores e crianças se sensibilizem com o outro. De modo a não deixarem, nem criança e nem bonecos, em um canto da 
sala ou na prateleira por ser diferente de si, por ser o outro, aquele que precisa viver com a sua diferença. Portanto, aprendemos o quanto tem sido significativo para professores e bebês viverem aprendizagens relacionadas à cultura afro-brasileira, independente de estar ou não um bebê-negro presente na sala de aula.

Ensinar as crianças pequenas a apreciarem seus corpos negros, bem como outros modos de se vestir e de arrumar os cabelos, por exemplo, nos leva a pensar que as experiências vividas na infância produzem, de algum modo, efeito no que nos tornamos, no nosso vir a ser. Tratar com as crianças sobre as questões raciais desde o berçário nos permitiu problematizar cada vez mais sobre esse tema e seu efeito na vida dos bebês. E continuar perguntando: como esses são afetados pelos múltiplos modos de vê-los como bebês-negros? Pensando sobre essa questão, concordamos com Sousa (2014, p.143) ao discorrer que "O viver, o estar em relação, o linguajar, o emocionar, o sentir, o tocar, o reconhecer, o negar, são dimensões de uma mesma espiral que se move congruente com os afetos vivenciados pelo ser humano em sua práxis existencial”.

Continuamos a nos indagar: o 'como' e 'o que' falamos com os bebês negros da sala? Como esses nos tocam, nos emocionam ou nos aborrecem? Como os sentimos, ou o reconhecemos como alguém que muitas vezes é o último a ser atendido na troca de fralda ou a ter seu nariz limpo? Como alguém que não se reconhece nas imagens expostas nas paredes da escola ou nos brinquedos disponíveis na sala?

A partir dessas experiências no berçário, entendemos que é possível apresentar para as crianças, desde muito cedo, os descaminhos, os modos de embelezamentos e estéticas de muitas raças, para então inverter o rumo dos "processos de subjetivação que ocorrem na escola e constituem a criança negra de maneira subalternizada e inferiorizada". (OLIVEIRA e ABRAMOWICZ, 2010, p.210).

A importância das propostas tão brevemente aqui apresentadas está relacionada ao fato de que "na educação infantil, o racismo aparece nas relações afetivas e corporais entre adultos e crianças e nas brincadeiras espontâneas destas, já que sabemos que o jogo é uma prática fundamental nessa faixa etária" (OLIVEIRA; ABRAMOWICZ, 2010, p.221). Nesse sentido, Dias (2012, p. 669) afirma que "É o toque e a proximidade física dos corpos negros que são evitados pelas crianças brancas".

Embora, durante a realização da brincadeira, muitas crianças não tenham mencionado por meio da oralidade, o fato de as bonecas serem negras, acreditamos que imagens de pessoas negras, tanto quanto as cores vibrantes de seus adereços, sendo apresentadas nos brinquedos, de algum 
modo, sinalizavam para elas, principalmente para os bebês-negros, que tal diferença é positiva. As crianças, embora não tenham usado a linguagem oral, expressaram, através de gestos, risos e toques o prazer que tais materiais e brinquedos lhes aguçavam a curiosidade e provocavam prazer.

As práticas das alunas desse grupo da Pedagogia contribuíram para romper com o silêncio da temática racial na rotina de muitos berçários e com o vazio racial nos espaços das escolas pesquisadas. Metodologicamente, elas também mostraram a inexistência de um "modo igual" para se pensar uma educação antirracista no berçário. Inventaram diferentes modos de levar as culturas africanas e afro-brasileiras para as brincadeiras das e com as crianças. Ou seja, mostraram ser possível promover práticas norteadoras de uma educação antirracista a partir de interações e brincadeiras desde os berçários.

\section{CONSIDERAÇÕES FINAIS}

Este estudo mostrou uma ação coletiva que envolveu pesquisadores, estudantes de Pedagogia, professoras e gestoras de Escolas de Educação Infantil para fazer funcionar os dois eixos apontados nas DCNEI como orientadores das propostas pedagógicas - as interações e as brincadeiras, a favor da promoção da igualdade racial.

Ao levarem às crianças, materiais alusivos às culturas africanas e afro-brasileiras, tais como bonecas princesas, fantoches, dedoches, tapetes, cortinas, livros de histórias e músicas, as alunas mostraram a possibilidade de apresentar tais culturas a partir de sua positividade, ou seja, o colorido das estampas, o gingado das danças, o gosto de sua comida, o batuque de suas músicas, a afetividade do ninar, fazer cafuné, acarinhar, tão bem colocado pela cultura afro-brasileira.

Ainda cabe destacar que essa pesquisa promoveu uma aproximação entre as escolas de Educação Infantil e as instituições de formação de professores no sentido de trocarem experiências acerca das possibilidades e dificuldades de juntas desenvolverem projetos que promovam a igualdade racial, pois essa necessária igualdade torna-se mais lenta e difícil a partir de ações isoladas que ocorrem aqui ou ali, em momentos pontuais. Há, ainda, expectativa de que as reflexões e as experiências apresentadas inspirem outras práticas antirracistas na educação infantil.

Entendemos como necessário, no contexto da educação de crianças, não só o das crianças brasileiras, mas de toda a cultura miscigenada, que sejam criadas condições para que as crianças negras e não negras possam viver plena e intensamente suas infâncias e a celebração das suas diferentes raças no dia a dia das escolas, desde o berçário. Educar na e para a igualdade racial na Educação Infantil não exige uma grande revolução, mas, como nos ensina Foucault, requer 
pequenas revoltas diárias (In: VEIGA-NETO, 2005). Tais revoltas, no contexto que discutimos neste estudo, podem atravessar a pesquisa, a formação de professores, a gestão, a docência na educação das crianças.

Estamos chegando em um momento de nosso país que essas pequenas revoltas diárias deverão estar cada vez mais presentes nos trabalhos pedagógicos desde os pequenos, pois precisamos assumir, como afirma Fischer (2002), a vitalidade de nossas investigações, sem passarmos à margem dos problemas sociais, institucionais, educacionais, econômicos e de governança. As ações desenvolvidas nas escolas infantis, através desta pesquisa, produziram, não só nas crianças, nas alunas, nas professoras e gestoras, mas em nós mesmas, outras formas de existência.

A pesquisa possibilitou que ficássemos cada vez mais atentas ao 'como' os bebês se manifestavam em suas diferentes linguagens para expressarem aquilo que entendiam sobre experiências com materiais tão diferentes daqueles que a visualidade da escola cotidianamente apresentava. Mostraram o quanto a vivência com tais visualidades torna-se um campo privilegiado para as intervenções pedagógicas que buscam uma educação antirracista e mais humana.

\section{REFERÊNCIAS}

BARBOSA, M. C. S. As especificidades da ação pedagógica com os bebês. Brasília, MEC/Secretaria de Educação Básica, 2010. Disponível em: file:///C:/Users/user/Downloads/asespecificidadesdaacaopedagogica\%20(3).pdf . Acesso em 16 fev. 2015.

BARBOSA, M. C. S; RICHTER, S. R. S. Desenvolvimento da Criança de 0 a 3 anos. Qual o currículo para bebês e crianças bem pequenas. In.: Educação de Crianças em Creche. Ano XIX, No 15 - outubro/2009. Ministério da Brasil. Disponível

em: https://www.researchgate.net/profile/Ana_Soares_da_Silva/publication/257362813_Apresentacao_da_Serie_Educacao de_Criancas_em_Creche/links/0deec525074c419b85000000.pdf?inViewer=0\&pdfJsDownload=0\&origin=publication_ detail. Acesso em 16 fev. 2015.

BRASIL. Constituição da República Federativa do Brasil. São Paulo: Imprensa Oficial do Estado, 1988.

Lei $\mathbf{n}^{\circ}$ 8.069/90, de 13 de julho de 1990. Estatuto da Criança e do Adolescente. São Paulo: CBIA-SP, 1991.

Lei $\mathbf{n}^{\circ}$ 9.394, de 20 de dezembro de 1996. Lei de Diretrizes e Bases da Educação.

Resolução CNE/CEB no 5/2009. Diretrizes Curriculares Nacionais para a Educação Infantil. Conselho Nacional de Educação. Brasília, DF: Diário Oficial da União, 18 dez de 2009.

. Ministério da Educação. Secretaria de Educação Básica. Diretrizes Curriculares Nacionais para a Educação Infantil. Secretaria de Educação Básica. Brasília: MEC, SEB, 2010.

Lei 10.639/2003. Altera a Lei n. 9.394, de 20 de dezembro de 1996, que estabelece as diretrizes e bases da educação nacional, para incluir no currículo oficial da Rede de Ensino a obrigatoriedade da temática "História e Cultura Afro-Brasileira", e dá outras providências. Poder Legislativo, DOU nº/02, seção I, p. I, Brasília, 2003.

Educação infantil e práticas promotoras de igualdade racial / [coordenação geral Hédio Silva Jr., Maria Aparecida Silva Bento, Silvia Pereira de Carvalho]. - São Paulo: Centro de Estudos das Relações de Trabalho e Desigualdades - CEERT :Instituto Avisa lá - Formação Continuada de Educadores, 2012. 
CORREA, A. Noal. Bebês produzem música? O brincar musical de bebês em berçário. Tese de Doutorado Programa de Pós-Graduação em Educação, Faculdade de Educação, Universidade Federal do Rio Grande do Sul, Porto Alegre, 2013.

DIAS, L. R. Formação de Professores, educação Infantil e diversidade étnico-racial: saberes e fazeres nesse processo. In.: Revista Brasileira de Educação, v. 17, n. 51, set/dez 2012, p. 661- 749.

DORNELLES, L. V.; KAERCHER, G. E. P. da S. (orgs.). Qual a cor da cultura na educação infantil? III Seminário Grupecci. Universidade Federal de Sergipe: Aracaju. De 22 a 24 de agosto de 2012.

DORNELLES, L. V.; MARQUES, C. M. Pedagogias da racialidade: modos de se constituir crianças negras em escolas de educação infantil do Brasil. In.: Propuesta Educativa, v. 1, n. 43; ano 24, v. 1, jun 2015, p.113-122.

FISCHER, R. Verdades em suspenso: Foucault e os perigos a enfrentar. IN: COSTA, Marisa (org.). Caminhos investigativos II: outros modos de pensar e fazer pesquisa em educação. Rio de Janeiro: DP\&A, 2002, p.49-71.

FLORIANÓPOLIS. Matriz Curricular para a Educação das Relações Étnico-Raciais na Educação Básica. Prefeitura Municipal de Florianópolis. Secretaria Municipal de Educação. Florianópolis, SC. 2016.

FOUCAULT, M. Sobre a genealogia da ética: uma revisão do trabalho. IN: DREYFUS, H. e RABINOW, P. Michel Foucault, uma trajetória filosófica. Para além do estruturalismo e da hermenêutica. Rio de Janeiro: Forense, 1995.

GOBBATO, C. Os bebês estão por todos os espaços!: um estudo sobre a educação de bebês nos diferentes contextos de vida coletiva da escola infantil. Porto Alegre: UFRGS, 2011. Dissertação de Mestrado - Programa de PósGraduação em Educação, Faculdade de Educação, Universidade Federal do Rio Grande do Sul, Porto Alegre, 2011.

GOMES, N. L. Educação e relações raciais: refletindo sobre algumas estratégias de atuação. In.: BRASIL. Superando o Racismo na escola. $2^{a}$ edição revisada / KabengeleMunanga, organizador. - [Brasília]: Ministério da Educação, Secretaria de Educação Continuada, Alfabetização e Diversidade, 2005, p. 143-154.

MALLMANN, E. Materiais potencializadores e os bebês-potência: possibilidades de experiências sensoriais e sensíveis no contexto de um berçário. Porto Alegre: UFRGS, 2015. Dissertação de Mestrado - Programa de PósGraduação em Educação, Faculdade de Educação, Universidade Federal do Rio Grande do Sul, Porto Alegre, 2015.

MARQUES, C. M. Experiência com bonecas anormais no curso de pedagogia: construindo modos de ser professora. Porto Alegre: UFRGS, 2013. Tese de Doutorado - Programa de Pós-Graduação em Educação, Faculdade de Educação, Universidade Federal do Rio Grande do Sul, Porto Alegre, 2013.

OLIVEIRA, F. de; ABRAMOWICZ, A. Infância, Raça e "Paparicação". In.: Educação em Revista. Belo Horizonte, v.26, n.02, ago. 2010, p. 209-226.

RICHTER, S. R. S.; BARBOSA, M. C. S. Os bebês interrogam o currículo: as múltiplas linguagens na creche. Educação, Santa Maria, v. 35, n. 1, p. 85-96, jan./abr. 2010. Disponível em: http://www.ufsm.br/revistaeducacao.

TOURAINE, A. Pensar de outro modo. Lisboa: Instituto Piaget, 2007.

VARGAS, G. Bebês em suas experiências primeiras: perspectivas para uma escola da infância. Porto Alegre: UFRGS, 2014. Tese de Doutorado - Programa de Pós-Graduação em Educação, Faculdade de Educação, Universidade Federal do Rio Grande do Sul, Porto Alegre, 2014.

VEIGA-NETO, A. Foucault e a Educação. Belo Horizonte: Autêntica, 2005. 


\section{QUEM DISSE QUE AS QUESTÕES RACIAIS NÃO AFETAM OS BEBÊS?}

RESUMO

Este artigo trata dos modos de apresentação de culturas afro-brasileiras às crianças de 0-3 anos em escolas da região metropolitana de Porto Alegre. Discute o trabalho pedagógico relacionado a tais culturas, com o objetivo de implementar as Diretrizes Curriculares Nacionais para a Educação Infantil (2009). Em um primeiro momento, foram feitas entrevistas semiestruturadas com gestores e professores e, em um segundo momento, as alunas de Pedagogia realizaram práticas nos berçários. 0 estudo sinalizou a importância de que sejam ampliadas, nos cursos de formação de professores, as discussões que tratam sobre a potência dos bebês e sobre a importância da inserção de práticas promotoras de igualdade racial no cotidiano da escola infantil na busca de uma educação antirracista.

Palavras-chave: Bebês; Igualdade racial; Diretrizes Curriculares Nacionais para a Educação Infantil.

\section{WHO HAS SAID THAT RACIAL ISSUES DO NOT AFFECT BABIES?}

\section{ABSTRACT}

This paper is about ways of introducing African-Brazilian cultures to zero- to three-year-old children in schools in Porto Alegre metropolitan area. It discusses pedagogical work concerning these cultures aiming to put National Curriculum Guidelines for Children Education (2009) into practice. First we conducted semi-structured interviews with managers and teachers and later pedagogy students took practices in nurseries. The study pointed to the significance for them to be expanded in teacher training courses, discussions addressing babies and the importance of introducing practices promoting racial equality in children schools in search of an antiracist education.

Keywords: Babies; Racial equality; National Curriculum Guidelines for Children Education

\section{?QUIÉN DIJO QUE LAS CUESTIONES RACIALES NO AFECTAN LOS NENES?}

\section{RESUMEN}

Este artículo trata de los modos de presentación de culturas afrobrasileñas a los niños de 0-3 años en escuelas de la región metropolitana de Porto Alegre. Discute el trabajo pedagógico relacionado a tales culturas, con el objetivo de implantar las Diretrizes Curriculares Nacionais para a Educação Infantil (2009). En un primer momento, fueron hechas entrevistas semiestructuradas con gestores y maestros y, en un según momento, las alumnas de Pedagogía realizaron prácticas en los nidos. El estudio señalizó la importancia de que sean ampliadas, en los cursos de formación de maestros, las discusiones que tratan sobre la potencia de los nenes y sobre la importancia de la inserción de prácticas promotoras de igualdad racial en el cotidiano de la escuela infantil en la búsqueda de una educación antirracista.

Palabras-llave: Nenes; Igualdad racial; Diretrizes Curriculares Nacionais para a Educação Infantil. 